\title{
A lower cost method of preparing corn stover for Irpex lacteus treatment by ensiling with lactic acid bacteria
}

\author{
Sasa Zuo ${ }^{1}$, Di Jiang ${ }^{1}$, Dongze Niu ${ }^{1}$, Mingli Zheng ${ }^{1}$, Ya Tao ${ }^{1}$, and Chuncheng $\mathrm{Xu}^{1 \text {,* }}$
}

* Corresponding Author: Chuncheng Xu Tel: +86-10-62736480, Fax: +86-10-62737997,

E-mail: xucc@cau.edu.cn

${ }^{1}$ College of Engineering, China Agricultural University, Beijing 100083, China

ORCID

Sasa Zuo

https://orcid.org/0000-0002-7204-856X

Di Jiang

https://orcid.org/0000-0002-7215-9286

Dongze Niu

https://orcid.org/0000-0001-6554-885X

Mingli Zheng

https://orcid.org/0000-0003-3281-2831

Ya Tao

https://orcid.org/0000-0002-4030-8494

Chuncheng Xu

https://orcid.org/0000-0003-0219-3304

Submitted Apr 24, 2019; Revised Jul 12, 2019; Accepted Sept 18, 2019
Objective: This study investigated a method of preparing corn stover for Irpex lacteus (I. lacteus) treatment to improve its in vitro rumen degradability under non-sterile conditions. Methods: Corn stover was inoculated with Lactobacillus plantarum (L. plantarum), Lactobacillus buchneri (L. buchneri), and an equal mixture of these strains, and ensiled for 0, 3, 7, 14 , and 28 days. After each period, a portion of the silage was sampled to assess the silage quality, and another portion of the silage was further treated with I. lacteus at $28^{\circ} \mathrm{C}$ for $28 \mathrm{~d}$. All the samples were analyzed for fermentation quality, chemical composition, and in vitro gas production (IVGP) as a measure of rumen fermentation capacity.

Results: Lactic acid bacteria (LAB) was found to improve the silage quality of the corn stover, and the corn stover silage inoculated with $L$. plantarum produced more lactic acid and higher IVGP than other silage groups. The I. lacteus colonies flourished in the early stage of corn stover silage, especially on the 3 -d corn stover silage inoculated with both $L$. plantarum and L. buchneri. This led to an $18 \%$ decrease in the acid detergent lignin content, and a $49.6 \%$ increase in IVGP compared with the raw stover.

Conclusion: The combination of ensiling with the mixed LAB inoculation and I. lacteus treatment provided a cost-effective method for the improvement of the IVGP of corn stover from $164.8 \mathrm{~mL} / \mathrm{g}$ organic matter $(\mathrm{OM})$ to $246.6 \mathrm{~mL} / \mathrm{g} \mathrm{OM}$.

Keywords: Ensiling; Irpex Lacteus; Corn Stover; Sterilization; In vitro Gas Production

\section{INTRODUCTION}

Lignocellulosic biomass such as corn stover is an important substrate for ruminant feed. However, because lignocellulosic feeds contain recalcitrant lignin, which is intertwined with hemicellulose and cellulose, such feeds cannot be optimally used by ruminants. Therefore, effective treatment to decrease the recalcitrance of the corn stover is essential. Biological treatment using white-rot fungi is viable and safe alternative to other treatments [1]. However, the white-rot fungal treatment of biomass has been considered difficult to carry out on a large scale because of the costly process of sterilization before the fungal treatment [2].

To overcome the disadvantage of high-cost autoclave-based sterilization before the fungal treatment of the substrates, a few studies have been devoted to developing a biological treatment method that works under non-sterile conditions. Vasco-Correa et al [3] increased the inoculum ratio to $30 \%$ dry basis, which yielded a successful fungal treatment of non-sterile miscanthus by Ceriporiopsis subvermispora; however, it is difficult to domesticate the fungus, and a large amount of inoculum is required. Song et al [4] developed a novel method by disinfecting the stover in a $0.1 \%(\mathrm{w} / \mathrm{v})$ hydrated lime solution for $24 \mathrm{~h}$ at room temperature before fungal treatment of corn stover, however, a lot of water is wasted in the process of washing the alkaline corn stover until the $\mathrm{pH}$ is neutral, and the resulting 
alkaline solute is an environmental pollutant. Another method is to wash the corn stover after ensiling before applying the white-rot fungal treatment to increase biogas production [5] and enzymatic hydrolysis [6]. Although this method is effective and efficient, the washing step wastes both time and water.

Ensiling is a method commonly applied on farms to preserve animal feed for off-season use. During this process, epiphytic lactic acid bacteria (LAB) transforms soluble carbohydrates into lactic acid, thereby reducing the $\mathrm{pH}$ to around 4.0. The naturally occurring acidic conditions can inhibit the growth of undesirable microorganisms [7], and such conditions can also partially hydrolyze hemicellulose and cellulose [8]. The disadvantage of ensiling as a treatment is that it can only make small improvements in digestibility compared to other treatments. In addition, if the initial number of epiphytic LAB is low, the $\mathrm{pH}$ of the forages cannot be reduced rapidly [7], and the ensiled substrate is then susceptible to aerobic aeration, which causes loss of dry matter (DM) and appearance of toxic substances [9]. Therefore, the use of LAB inoculants is recommended. In recent years, homofermentative LAB species such as Lactobacillus plantarum (L. plantarum) and heterofermentative LAB such as Lactobacillus brevis are the main inoculants used in silage. Their different fermentation properties exhibit various effects on the silage quality [9]. However, no studies have been published, which compare homofermentative and heterofermentative $\mathrm{LAB}$, and a mixture of them on the effect of the corn stover silage quality.

The use of white-rot fungi as an additional treatment shows promise, especially some white-rot fungi that can prevail under acidic conditions [10]. Therefore, our hypothesis is that employing the acidophilic white rot fungal treatment of the ensilage corn stover could improve its in vitro rumen degradability without high cost sterilization. Irpex lacteus (I. lacteus), a kind of medicinal fungus, allows for efficient enzymatic conversion of the plant material and can forcefully degrade the acid detergent lignin (ADL) $[11,12]$. In the present study, I. lacteus was employed to treatment of corn stover silages inoculated with LAB to further increase its nutritional potential. The changes in the fermentation quality, numbers of microorganisms, and chemical composition during ensiling and after I. lacteus treatment, were analyzed to assess the effect of different LAB on the silage quality and the following fungal degradation characteristics. The in vitro gas production (IVGP) values of the intact, ensiled and fungal-treated-ensiled stover were compared to evaluate nutritional value of the stover.

\section{MATERIALS AND METHODS}

\section{Raw material}

Corn stover of the Grain and Forage corn variety was collected in October 2017 from farmland in Hebei Province, China. The stubble height of the corn stover was $20 \mathrm{~cm}$ and the aboveground plant including the stalks, leaves, rachis, and tassels. This material was initially air-dried at room temperature for one month. The stover was chopped to average sizes of $2 \mathrm{~cm}$ length, and then sealed in plastic bags and stored at room temperature for further use.

\section{Ensiling}

The moisture content of the prepared corn stover was adjusted to $70 \%$. After thorough mixing, it was separated into four groups, and each group received one of the following treatments: i) sterilized distilled water (CK), ii) L. plantarum (GenBank accession number: SUB3928584) at $1 \times 10^{5}$ colony forming units (CFU)/g of fresh matter (LP), iii) Lactobacillus buchneri (L. buchneri) strain (GenBank accession number: KY828224) at $1 \times 10^{5} \mathrm{CFU} / \mathrm{g}$ of fresh matter (LB), and iv) cells of $L$. plantarum and L. buchneri were mixed in an equal ratio at a concentration of $1 \times 10^{5} \mathrm{CFU} / \mathrm{g}$ of fresh matter (MIX). The various inocula were scattered in each group and mixed thoroughly by hands with sterile gloves were worn at room temperature, approximately two hundred grams of the preensiled material was packed into a plastic film bag silo (Hiryu $\mathrm{KN}$ type, $180 \times 260 \mathrm{~mm}$; Asahikasei, Tokyo, Japan), and this was followed by air removal using a vacuum sealer (BH 950; Matsushita, Tokyo, Japan). Silos were prepared in triplicate and stored at ambient temperature for $0,3,7,14$, and $28 \mathrm{~d}$.

\section{White-rot fungus of Irpex lacteus pre-culture and treatment}

The fungus of I. lacteus (CGMCC-5.809) was obtained from the China General Microbiological Culture Collection Center (Beijing, China), and was preserved on potato dextrose agar (PDA) slants at $4^{\circ} \mathrm{C}$. Initial cultures were developed on PDA plates at $28^{\circ} \mathrm{C}$ until mycelium covered the entire agar plates. The spawn was prepared by adding 20 pieces (approx. $1 \mathrm{~g}$ ) of colonized agar culture $\left(0.2 \mathrm{~cm}^{2}\right)$ to $200 \mathrm{~g}$ of sterilized $70 \%$ moisture content of wheat grains. The inoculated wheat grains were incubated at $28^{\circ} \mathrm{C}$ until all grains were colonized by mycelium. The spawn was stored at $4^{\circ} \mathrm{C}$ until further use. After unsealing at $0,3,7,14$, and $28 \mathrm{~d}, 100 \mathrm{~g}$ of silage was weighed into $25 \times 17 \mathrm{~cm}$ polyethylene bags (Miaojie, Wuxi, Jiangsu, China). Thereafter, $4 \mathrm{~g}$ of the pre-cultured wheat grains with $I$. lacteus were inoculated in $0,3,7,14$, and 28 $\mathrm{d}$ of ensiled corn stover. All bags were incubated at $28^{\circ} \mathrm{C}$ for $28 \mathrm{~d}$ in a controlled humidity chamber at $85 \%$ humidity. Triplicate samples of each silage group treated with I. lacteus were set as: CKI, LPI, LBI, and MIXI. The corn stover silages and the silages after treated with $I$. lacteus were analyzed for the changes in the quality of fermentation, chemical composition, and IVGP. 


\section{Fermentation quality and microbial enumeration}

To measure fermentation quality, $10 \mathrm{~g}$ of silage, with or without $I$. lacteus treatment was homogenized with $90 \mathrm{~mL}$ of sterilized distilled water and submerged for $3 \mathrm{~h}$ in the $4^{\circ} \mathrm{C}$ fridge, and then filtered through qualitative filter paper. The filtrates were used for determining $\mathrm{pH}$ and organic acid. The $\mathrm{pH}$ was measured using a glass electrode $\mathrm{pH}$ meter (S20K, Mettler Toledo, Greifensee, Switzerland), and the organic acid of lactic, acetic, propionic and butyric acid content was determined by HPLC (column: Shodex RS Pak KC-811, Showa Denko K.K., Kawasaki, Japan; detector: DAD, 210 nm, SPD20A, Shimadzu Co., Ltd, Kyoto, Japan; eluent: $3 \mathrm{mmol} / \mathrm{L}$ $\mathrm{HClO} 4,1.0 \mathrm{~mL} / \mathrm{min}$; temperature: $50^{\circ} \mathrm{C}$ ) using the procedures described by $\mathrm{Xu}$ et al [13].

Populations of microorganisms were measured through the spread-plate count method. The LAB were counted on Man Rogosa Sharpe agar (Difco Laboratories, Detroit, MI, USA) incubated at $37^{\circ} \mathrm{C}$ for $48 \mathrm{~h}$ under anaerobic conditions. Aerobic bacteria were counted on nutrient agar (Nissui-Seiyaku Ltd., Japan) incubated at $30^{\circ} \mathrm{C}$ for $48 \mathrm{~h}$ under aerobic conditions. Molds and yeasts were counted on PDA (Nissui-Seiyaku Ltd., Tokyo, Japan) plates incubated at $28^{\circ} \mathrm{C}$ for $72 \mathrm{~h}$ under aerobic conditions. The colonies were counted from the plates at appropriate dilutions, and the number was expressed as CFU per gram of fresh matter.

\section{Chemical analysis}

The DM content was determined by drying the materials in an oven at $65^{\circ} \mathrm{C}$ for $48 \mathrm{~h}$, and water soluble carbohydrates (WSC) content was determined using the method of Owens et al [14]. Fiber analysis was carried on air-dried, ground (1 $\mathrm{mm}$ ) material according to Van Soest et al [15], using an Ankom fiber analyser 2000 (ANKOM Technology, Macedon, New York, USA). Neutral detergent fiber (aNDF) was determined with heat stable amylase without adding sodium sulfite. The aNDF, acid detergent fiber (ADF), ADL were expressed inclusive of residual ash. Neutral detergent solute (NDS) content was calculated by subtracting the aNDF from 1,000 . The hemicellulose content was calculated as the difference between aNDF and ADF contents and the cellulose content was calculated as the difference between ADF and ADL contents. Absolute numbers were calculated according to Van Kuijk et al [16] using data on the remaining constant weight of airforced oven DM of the corn stover silage, with or without fungal treatment, and were expressed as gram and representative average values between the duplicates.

\section{In vitro gas production technique}

The IVGP was measured according to Menke and Steingass [17]. In summary, rumen fluid of fistulated Angus bullocks fed a corn silage, and wheat straw-based diet was mixed with a buffer solution under continuous flushing with $\mathrm{CO}_{2}$. Air dried samples $(220 \mathrm{mg}$ ) were incubated in $30 \mathrm{~mL}$ buffered rumen fluid for $72 \mathrm{~h}$ at $39^{\circ} \mathrm{C}$. The IVGP of all the samples was manually recorded at $0,2,4,6,8,10,12,16,20,24,30$, $36,42,48,60$, and $72 \mathrm{~h}$ of incubation, and related to the organic matter $(\mathrm{OM})$ content. The data shown here represent average values between the triplicates.

\section{Statistical analysis}

Data on fermentation quality, microbial counts, chemical compositions, with and without $I$. lacteus inoculation, were subjected to two-way analysis of variance analysis of variance with the fixed effects of silage pretreatments and storage periods using the generalized linear model (GLM) procedures of SPSS, version 21.0 (IBM Corp., Armonk, NY, USA). This was followed by Duncan's multiple range tests and significance was defined at a 0.05 probability level. The $72 \mathrm{~h}$ IVGP before and after a $28 \mathrm{~d}$ fungal treatment compared with the silages uninoculated with $\mathrm{LAB}$ was subjected to GLM analysis in SAS 9.2 with the following model:

$$
Y_{i j}=\mu+\alpha_{i}+\omega_{i j}
$$

in which $Y_{i j}$ is the observation $j$ for pretreatment $i ; \mu$ is the overall mean; $\alpha_{i}$ is the fixed effect of pretreatment $i ; \omega_{i j}$ is the random error.

\section{RESULTS AND DISCUSSION}

Fermentation properties and microbial components of corn stover silage before and after I. lacteus treatment The first part of the experiments was performed as part of a broad research effort aimed at determining the effect of different LAB inoculants on corn stover silage quality and which method of inoculation can be better provide a good nonsterile environment for white rot fungi further treatment of the stover. The changes in the $\mathrm{pH}$ and organic acid content of the corn stover during ensiling are shown in Table 1. The group of MIX has the lowest $\mathrm{pH}$, while the $\mathrm{CK}$ has the highest $\mathrm{pH}(\mathrm{p}<0.01)$, and the $\mathrm{pH}$ decreased quickly before day 7 and then stabilized. The lactic acid content in all the pretreatment samples increased at the initial stage of the silage, reached the highest $(\mathrm{p}<0.01)$ value on day 7 , and then decreased thereafter. These results are demonstrated that high LAB counts are needed to ensure a rapid and vigorous fermentation that results in a rapid decline in $\mathrm{pH}$ and accumulation of the lactic acid. In this study, the LP group had the highest $(\mathrm{p}<0.01)$ lactic acid content, for the $\mathrm{LAB}$ fermentation proceeded rapidly with $L$. plantarum, which resulted in the intensive and fast production of lactic acid and a rapid decrease in $\mathrm{pH}$, indicating that homofermentative LAB can significantly improve natural silage fermentation quality [18]. However, the homofermentative LAB inoculants can impair the aerobic 
Table 1. Changes in $\mathrm{pH}$ and organic acids ( $/ \mathrm{kg}$ dry matter) content of corn stover during the $28 \mathrm{~d}$ of ensilage

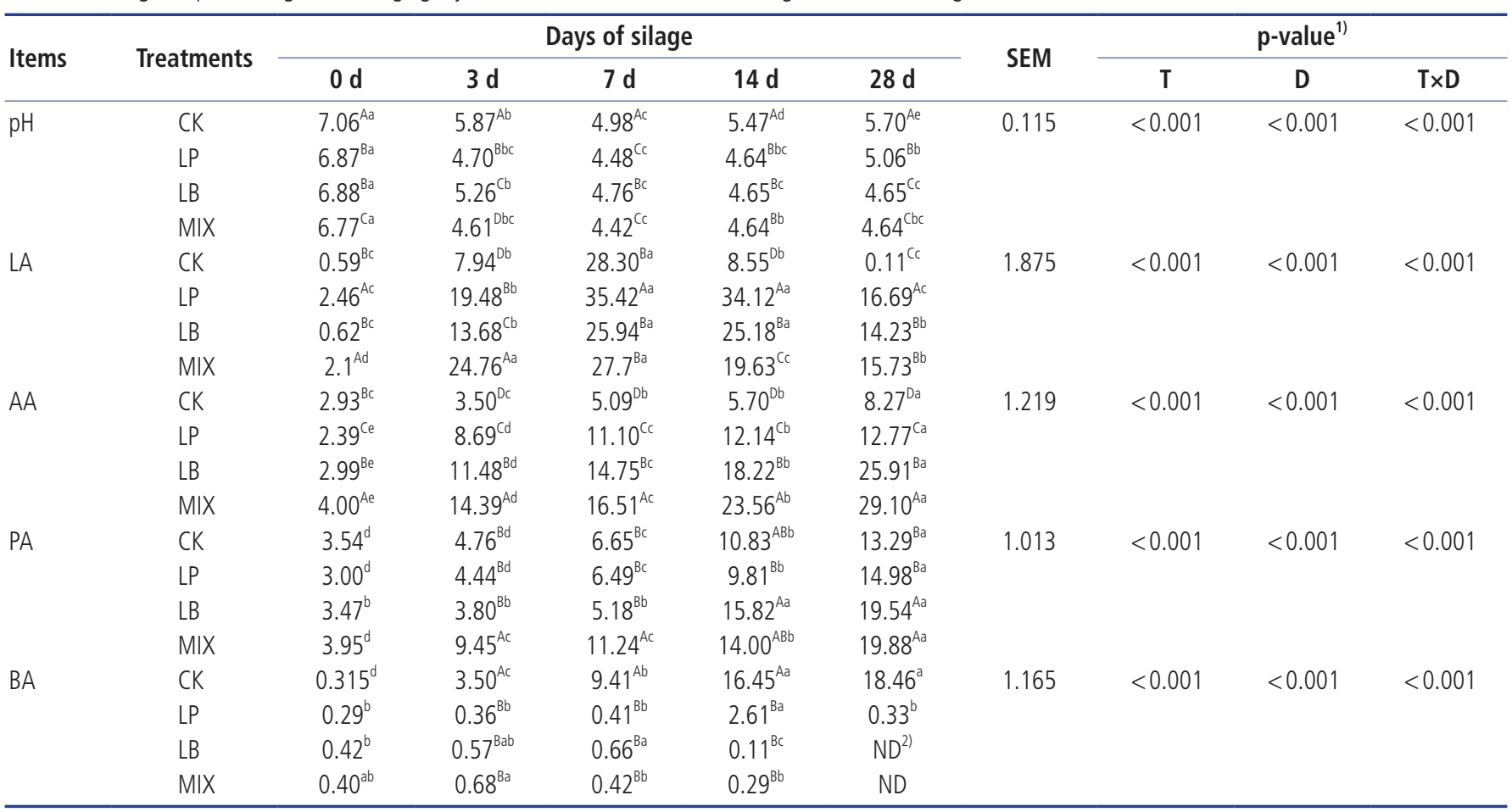

SEM, standard error of the mean; CK, silage uninoculated with lactic acid bacteria; LP, silage inoculated with Lactobacillus plantarum; LB, silage inoculated with Lactobacillus buchneri; MIX, silage inoculated with mixed L. plantarum and L. buchneri; LA, lactic acid; AA, acetic acid; PA, propionic acid; BA, butyric acid.

${ }^{1)} T$, effect of different pretreatment; $D$, effect of silage time; $T \times D$, interaction between pretreatment and silage time.

${ }^{2)} \mathrm{ND}$, not detected.

Means in the same row ${ }^{(-e)}$ ) or in the same column $\left({ }^{A-D}\right)$ with different superscripts differ $(p<0.05)$.

stability of silage, while the present result with a high acetic acid content in the LB group probably can improve aerobic stability of silage, for the heterofermentative lactic acid bacterium, such as L. buchneri, has been studied as an additive to improve the aerobic stability of silage by producing high levels of acetic acid in silage [19]. However, in this study, an even higher acetic acid content in MIX group indicates a stronger suppression potential of undesirable microorganisms inoculated with a mixture of LAB strains. Also, the MIX group had the total highest $(\mathrm{p}<0.01)$ propionic acid content, followed by the LB and then the LP. The CK had the lowest $(\mathrm{p}<0.01)$ acetic acid and propionic acid content. Moreover, the butyric acid content in the CK was significantly higher than that of the other three silage groups $(\mathrm{p}<0.01)$, indicating that the CK silage has probably undergone clostridial fermentation; therefore, the CK presented poor silage quality.

The fermentation characteristics after I. lacteus treatment are shown in Table 2. The $\mathrm{pH}$ of the CKI was highest $(\mathrm{p}<0.01)$, which was probably due to the poor silage quality and bad aerobic stability of the $\mathrm{CK}$, and thus it was easily contaminated by mold. The period of ensilage had no significant effect on the $\mathrm{pH}$ of each group's samples after the 28 - $\mathrm{d}$ fungal treatment; however, the shorter the ensilage period with the LAB inoculation, the more the I. lacteus thrived and the lower $\mathrm{pH}$ after the fungal treatment $(\mathrm{p}=0.023)$ which is most likely due to the initial $\mathrm{pH}$ of the silage and the amount of organic acid suitable for the fungus to germinate. As the silage period prolonged, the accumulation of organic acid or other components might have limited the growth of I. lacteus $[5,6]$. The lactic acid content of the silage samples decreased after the $28 \mathrm{~d}$ of the I. lacteus treatment, and the 3-d MIXI showed the highest lactic acid content $(\mathrm{p}<0.01)$. Acetic acid was only detected in the CKI and LPI. The propionic acid content of the CKI was higher than it was in the other groups $(\mathrm{p}<0.01)$. Butyric acid was not detected in any of the I. lacteus treatment samples. The organic acids decreased after the $I$. lacteus treatment, which was probably due to the aerobic microbes metabolizing lactic acid and butyric acid for their growth [20].

Silage that has been inoculated with LAB is commonly fed to ruminants because the $\mathrm{LAB}$ reproduction accumulates lactic acid, which is the key factor for ensuring good forge quality (both enhanced storage capacity and improved digestibility) during ensiling [21]. The initial epiphytic LAB and enterobacteria in corn stover were $1.4 \times 10^{5}$ and $5 \times 10^{8}$ $\mathrm{CFU} / \mathrm{g}$ fresh matter respectively. During ensiling, LAB as well as the aerobic bacteria number was determined (Figure 1a, b). In this study, the homofermentative LAB fermentation 
Table 2. pH and organic acids (g/kg dry matter) content after Irpex lacteus treatment of 3, 7, 14, and $28 \mathrm{~d}$ of corn stover silage

\begin{tabular}{|c|c|c|c|c|c|c|c|c|c|}
\hline \multirow{2}{*}{ Items } & \multirow{2}{*}{ Treatments } & \multicolumn{4}{|c|}{ Days of silage } & \multirow{2}{*}{ SEM } & \multicolumn{3}{|c|}{$p$-value ${ }^{1)}$} \\
\hline & & $3 d$ & $7 \mathrm{~d}$ & $14 \mathrm{~d}$ & $28 \mathrm{~d}$ & & $T$ & D & $T \times D$ \\
\hline \multirow[t]{4}{*}{$\mathrm{pH}$} & CKI & $6.76^{\mathrm{Aa}}$ & $6.10^{\mathrm{Ab}}$ & $5.61^{\mathrm{Ac}}$ & $5.62^{\mathrm{Ac}}$ & 0.104 & $<0.001$ & 0.142 & $<0.001$ \\
\hline & LPI & $4.73^{B C}$ & $4.79^{B b c}$ & $4.84^{\mathrm{Bb}}$ & $5.03^{\mathrm{ABa}}$ & & & & \\
\hline & LBI & $4.79^{B}$ & $4.84^{B}$ & $5.02^{B}$ & $4.94^{\mathrm{AB}}$ & & & & \\
\hline & MIXI & $4.63^{\mathrm{cb}}$ & $4.94^{\mathrm{Ba}}$ & $4.79^{\mathrm{Bab}}$ & $4.73^{\mathrm{Bb}}$ & & & & \\
\hline \multirow[t]{4}{*}{$L A$} & CKI & $2.30^{\mathrm{Ca}}$ & $1.42^{\mathrm{Bb}}$ & $1.52^{\mathrm{Bb}}$ & $0.91^{\mathrm{cc}}$ & 0.195 & $<0.001$ & $<0.001$ & $<0.001$ \\
\hline & LPI & $3.62^{A B a}$ & $3.03^{A b}$ & $2.08^{A c}$ & $1.09^{\mathrm{Cd}}$ & & & & \\
\hline & $L B \mid$ & $3.00^{\mathrm{BCa}}$ & $0.63^{\mathrm{Cd}}$ & $1.06^{\mathrm{Cc}}$ & $1.65^{\mathrm{Ab}}$ & & & & \\
\hline & MIXI & $4.0^{\mathrm{Aa}}$ & $0.74^{\mathrm{Cd}}$ & $2.55^{\mathrm{Bb}}$ & $1.33^{B C}$ & & & & \\
\hline \multirow[t]{4}{*}{ AA } & CKI & $N D^{2)}$ & ND & ND & 0.25 & - & - & - & - \\
\hline & LPI & ND & ND & ND & 0.43 & & & & \\
\hline & LBI & ND & ND & ND & ND & & & & \\
\hline & MIXI & ND & ND & ND & ND & & & & \\
\hline \multirow[t]{4}{*}{ PA } & CKI & 1.58 & 1.47 & 0.85 & 0.35 & - & - & - & - \\
\hline & LPI & ND & ND & 0.05 & 0.01 & & & & \\
\hline & LBI & ND & 1.38 & 0.30 & 0.11 & & & & \\
\hline & MIXI & ND & 0.94 & 0.45 & 0.30 & & & & \\
\hline \multirow[t]{4}{*}{ BA } & CKI & ND & ND & ND & ND & - & - & - & - \\
\hline & LPI & ND & ND & ND & ND & & & & \\
\hline & LBI & ND & ND & ND & ND & & & & \\
\hline & MIXI & ND & ND & ND & ND & & & & \\
\hline
\end{tabular}

SEM, standard error of the mean; CKI, I. lacteus treatment of corn stover silage uninoculated with LAB; LPI, I. lacteus treatment of silage inoculated with Lactobacillus plantarum; LBI, I. lacteus treatment of silage inoculated with Lactobacillus buchneri; MIXI, I. lacteus treatment of silage inoculated with mixed L. plantarum and L. buchneri; LA, lactic acid; AA, acetic acid; PA, propionic acid; BA, butyric acid.

${ }^{1)} T$, effect of $I$. lacteus treatment of different silges; $D$, effect of silage time; $T \times D$, interaction between treatment and silage time.

${ }^{2)} \mathrm{ND}$, not detected.

Means in the same row ${ }^{\left({ }^{-d}\right)}$ ) or in the same column $\left(^{A-c}\right)$ with different superscripts differ $(p<0.05)$.

proceeded rapidly by adding L. plantarum, which produced the highest numbers of the LAB (Figure 1a). However, the peak value of LAB numbers appearing on the 3-d MIX group and the peak at day 7 for the other three groups indicate that MIX can enter the silage stable period more quickly than other groups. The aerobic bacteria number was observed to decrease during ensiling of corn stover; an especially rapid decrease was observed at the beginning of the MIX group $(\mathrm{p}<0.01)$ (Figure $1 \mathrm{~b})$. Moreover, the aerobic bacteria number in the inoculated LAB silages was lower than in the CK group during the process ( $<<0.01$; Figure $1 \mathrm{~b})$. Indeed, by the end of the MIX process, the number of aerobic bacteria had decreased to $3 \times 10^{5} \mathrm{CFU} / \mathrm{g}$ fresh matter (Figure $1 \mathrm{~b}$ ), which indicates a significantly inhibitory effect of mixed LAB on the growth of aerobic bacteria. The decrease in the numbers of aerobic bacteria, yeast and mold (data not shown) after ensiling, was attributed to the stress from the anaerobic environment, organic acids and low $\mathrm{pH}$ [22]. Therefore, for development of functional bacterial inoculants, both homofermentative and heterofermentative LAB should be involved.

Aerobic stability of silage is a key factor in ensuring that silage provides well-preserved nutrients to animals without contamination of mold spores and toxins. As the corn stover silage without $\mathrm{LAB}$ inoculation (0-d CK) has the poor aerobic stability, which was completely contaminated by mold a few days after treatment with I. lacteus, no analysis of microorganism numbers, fermentation quality, chemical composition, and gas production of the I. lacteus treatment of the 0 - $\mathrm{d}$ silages was done. The numbers of LAB decreased, and the number of aerobic bacteria increased overall after I. lacteus treatment of the different days of silage compared with the stover before the fungal treatment (Figure 1c and d), because when the silage bags were opened, acid-resistant aerobic bacteria began to multiply growth under aerobic condition, which suppressed the LAB growth. The 7-d LPI had the lowest LAB numbers $\left(3.25 \times 10^{5} \mathrm{CFU} / \mathrm{g}\right.$ fresh matter $)(\mathrm{p}<0.01$; Figure $1 \mathrm{c})$. However, the 3-d MIXI had the highest LAB numbers (3.53x $10^{8} \mathrm{CFU} / \mathrm{g}$ fresh matter) $(\mathrm{p}<0.05$; Figure $1 \mathrm{c})$, which was most likely due to the higher aerobic stability of this time frame and this treatment. The numbers of aerobic bacteria in all of the groups was above $1 \times 10^{8} \mathrm{CFU} / \mathrm{g}$ fresh matter after the $I$. lacteus treatment, and there is no difference of the number between the different ensilage periods combined with $I$. lacteus treatment (Figure 1d). Although some of the multiply growth of acid-resistant microorganisms potentially inhibited the growth of white-rot fungi, it has been reported that I. lacteus 

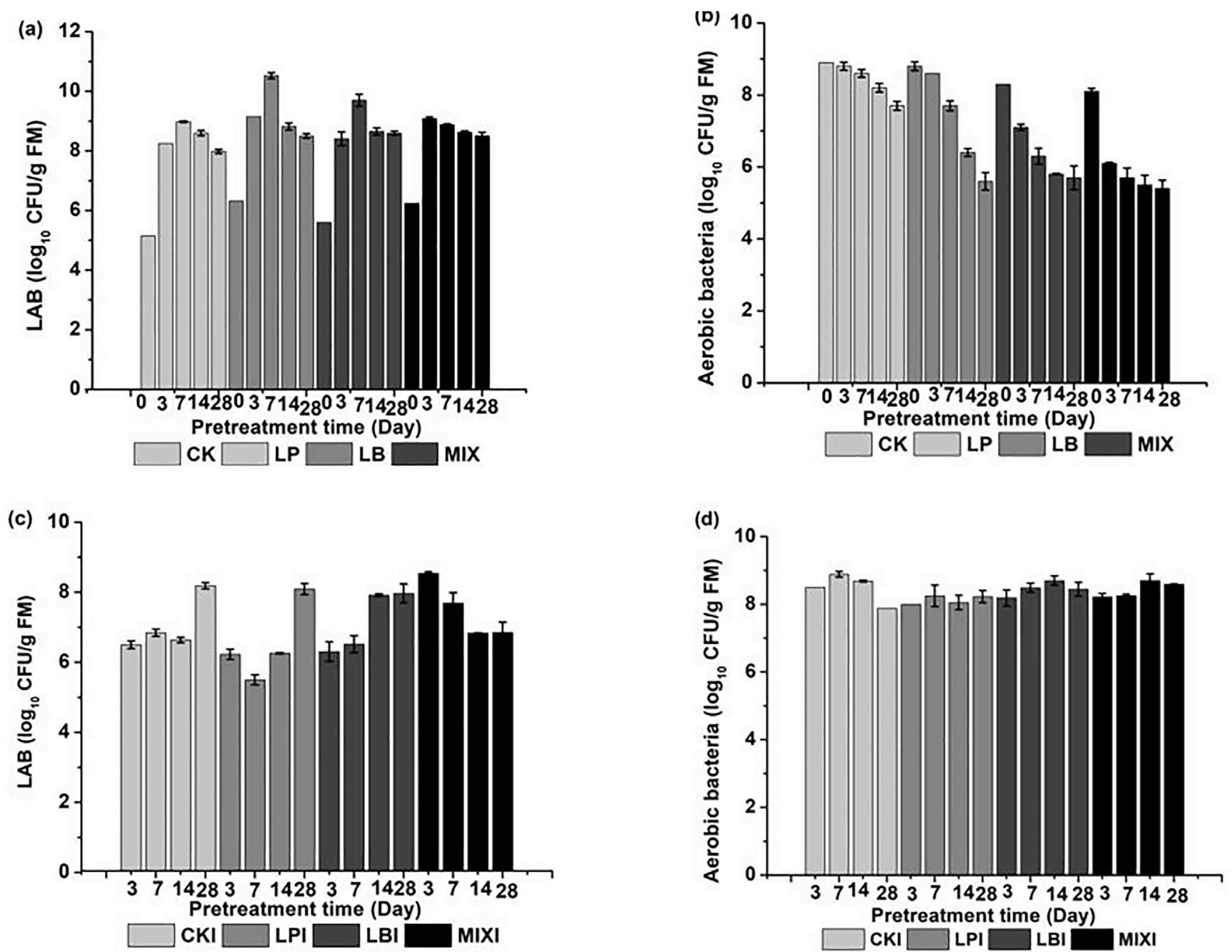

Figure 1. The numbers of $L A B(a)$, aerobic bacteria (b) at $0,3,7,14,28 \mathrm{~d}$ of corn stover ensiling, and the $L A B(c)$, aerobic bacteria (d) numbers after the Irpex lacteus treatment of different periods of the silage. $L A B$, lactic acid bacteria; $C K$, silage uninoculated with $L A B$; $L P$, silage inoculated with Lactobacillus planturam; $L B$, silage inoculated with Lactobacillus buchneri; MIX, silage inoculated with the mixed L. planturam and L. buchneri; CKI, I. lacteus treatment of corn stover silage uninoculated with LAB; LPI, I. lacteus treatment of silage inoculated with Lactobacillus plantarum; LBI, I. lacteus treatment of silage inoculated with Lactobacillus buchneri; MIXI, I. lacteus treatment of silage inoculated with mixed L. plantarum and L. buchneri. Data are presented as means of three replicates (mean \pm standard deviation).

has a stronger ability to compete with these bacteria, which might be the reason why I. lacteus can grow well in the ensiled corn stover that contain high amounts of aerobic bacteria [23]. Moreover, the high abundance of I. lacteus in the MIXI and the low abundance of this fungus in the CKI indicated that the inoculation of $\mathrm{LAB}$ provided a good environment for the growth of I. lacteus, which made I. lacteus became the dominant fungus in the corn stover silage (Supporting information).

Chemical analysis of corn stover silage before and after I. lacteus treatment

The aNDF, ADF, ADL, NDS, and WSC content of the corn stover used in the silage fermentation is $742.9 \pm 5.9,462.6 \pm 4.2$, $86.9 \pm 1.6,257.1 \pm 5.9$, and $19.8 \pm 1.3$, respectively. For all silage groups, the absolute weight of DM, cellulose, hemicellulose, ADL, NDS, and WSC decreased with the greater ensilage period (Table 3). The efficient conservation of corn stover silage with minimal DM losses during the storage period is important to provide ruminants with essential nutrients. In this study, the DM losses in corn stover silage during ensiling were small and within the acceptable range of $10 \%$. The absolute weight of the DM of the CK was the lowest after 28-d ensilage period $(\mathrm{p}<0.01)$, and the DM weight for LP and LB was equivalent but was higher than the DM weight of MIX $(p=0.024)$. The amount of cellulose in the LP was lower than the amount in the LB, but higher than MIX $(\mathrm{p}<0.01)$. No difference was found in the weight of hemicellulose or ADL between the different silage groups. The loss of cellulose and hemicellulose observed in corn stover silage during 
Table 3. Changes of chemical composition ( $\mathrm{g}$ ) of corn stover during the $28 \mathrm{~d}$ of ensilage

\begin{tabular}{|c|c|c|c|c|c|c|c|c|c|c|}
\hline \multirow{2}{*}{ Items } & \multirow{2}{*}{ Pretreatments } & \multicolumn{5}{|c|}{ Days of silage } & \multirow{2}{*}{ SEM } & \multicolumn{3}{|c|}{ p-value ${ }^{1)}$} \\
\hline & & $0 \mathrm{~d}$ & $3 d$ & $7 d$ & $14 \mathrm{~d}$ & $28 d$ & & $T$ & D & $T \times D$ \\
\hline \multirow[t]{4}{*}{$\mathrm{DM}$} & CK & $1,000^{\mathrm{a}}$ & $970^{\mathrm{Bb}}$ & $938^{\mathrm{Cc}}$ & $920^{\text {cd }}$ & $918^{\mathrm{cd}}$ & 3.93 & $<0.001$ & $<0.001$ & $<0.001$ \\
\hline & $L P$ & $1,000^{\mathrm{a}}$ & $983^{A b}$ & $980^{A b}$ & $971^{A c}$ & $945^{\mathrm{Bd}}$ & & & & \\
\hline & $L B$ & $1,000^{\mathrm{a}}$ & $984^{A b}$ & $977^{A b}$ & $967^{A c}$ & $963^{A C}$ & & & & \\
\hline & MIX & $1,000^{\mathrm{a}}$ & $982^{A b}$ & $962^{B C}$ & $957^{B C}$ & $956^{B C}$ & & & & \\
\hline \multirow[t]{4}{*}{ Cell } & CK & $378^{\mathrm{a}}$ & $373^{\mathrm{Aa}}$ & $360^{B b}$ & $350^{B C}$ & $346^{B C}$ & 1.52 & $<0.001$ & $<0.001$ & $<0.001$ \\
\hline & $L P$ & $378^{\mathrm{a}}$ & $360^{B b}$ & $357^{\mathrm{Bb}}$ & $357^{\mathrm{Bb}}$ & $356^{\mathrm{Bb}}$ & & & & \\
\hline & $L B$ & 378 & $378^{A}$ & $369^{A}$ & $372^{A}$ & $375^{A}$ & & & & \\
\hline & MIX & $378^{a}$ & $347^{\mathrm{cc}}$ & $355^{B b}$ & $354^{B b}$ & $347^{B C}$ & & & & \\
\hline \multirow[t]{4}{*}{$H C$} & CK & $266^{a}$ & $247^{b}$ & $241^{b}$ & $239^{b}$ & $237^{b}$ & 1.63 & 0.075 & $<0.001$ & 0.899 \\
\hline & $L P$ & $266^{a}$ & $254^{b}$ & $246^{b}$ & $249^{b}$ & $246^{b}$ & & & & \\
\hline & LB & $266^{a}$ & $261^{a}$ & $250^{b}$ & $244^{b c}$ & $242^{c}$ & & & & \\
\hline & MIX & $266^{\mathrm{a}}$ & $255^{b}$ & $242^{b c}$ & $237^{c}$ & $232^{c}$ & & & & \\
\hline \multirow[t]{4}{*}{$A D L$} & CK & 86.9 & 85.3 & 81.1 & 79.8 & 78.0 & 0.64 & 0.125 & $<0.001$ & 0.357 \\
\hline & $L P$ & $86.9^{a}$ & $74.6^{b}$ & $79.0^{b}$ & $76.6^{b}$ & $75.5^{b}$ & & & & \\
\hline & $L B$ & $86.9^{a}$ & $76.1^{b}$ & $76.6^{b}$ & $77.7^{b}$ & $76.7^{b}$ & & & & \\
\hline & MIX & 86.9 & 80.2 & 78.7 & 80.3 & 80.5 & & & & \\
\hline \multirow[t]{4}{*}{ NDS } & CK & 265 & $260^{B}$ & $258^{B}$ & $254^{C}$ & $253^{B}$ & 1.98 & $<0.001$ & $<0.001$ & $<0.001$ \\
\hline & $L P$ & $275^{b}$ & $297^{\mathrm{Aa}}$ & $296^{\mathrm{Aa}}$ & $283^{\mathrm{Aa}}$ & $268^{A b}$ & & & & \\
\hline & $L B$ & $270^{b}$ & $273^{B b}$ & $283^{\mathrm{Aa}}$ & $271^{\mathrm{Bb}}$ & $265^{A c}$ & & & & \\
\hline & MIX & $273^{b c}$ & $298^{\mathrm{Aa}}$ & $286^{\mathrm{Ab}}$ & $285^{A b}$ & $266^{A C}$ & & & & \\
\hline \multirow[t]{4}{*}{ WSC } & CK & $19.8^{\mathrm{a}}$ & $8.1^{A b}$ & $7.2^{\mathrm{Abc}}$ & $6.9^{\mathrm{Abc}}$ & $6.3^{A C}$ & 0.74 & $<0.001$ & $<0.001$ & $<0.001$ \\
\hline & $L P$ & $22.1^{\mathrm{a}}$ & $8.7^{\mathrm{Ab}}$ & $8.4^{\mathrm{Ab}}$ & $8.0^{\mathrm{Ab}}$ & $7.6^{\mathrm{Ab}}$ & & & & \\
\hline & LB & $20.4^{a}$ & $6.7^{\mathrm{Bb}}$ & $2.2^{B C}$ & $1.1^{B c d}$ & $0.4^{\mathrm{Cd}}$ & & & & \\
\hline & MIX & $20.8^{a}$ & $4.1^{\mathrm{cb}}$ & $2.0^{B C}$ & $2.6^{B C}$ & $2.5^{B C}$ & & & & \\
\hline
\end{tabular}

SEM, standard error of the mean; DM, dry matter; CK, silage uninoculated with LAB; LP, silage inoculated with Lactobacillus plantarum; LB, silage inoculated with Lactobacillus buchneri; MIX, silage inoculated with mixed L. plantarum and L. buchneri; Cell, cellulose; HC, hemicellulose; ADL, acid detergent lignin; NDS, neutral detergent solute; WSC, Water soluble carbohydrate.

${ }^{1)} T$, effect of different pretreatment; $D$, effect of silage time; $T \times D$, interaction between pretreatment and time.

Means in the same row ${ }^{(-d)}$ ) or in the same column ${ }^{\left(A^{-C}\right)}$ ) with different superscripts differ $(p<0.05)$.

ensiling is consistent with studies conducted by Yahaya et al [24], which suggests that cellulose and hemicellulose could serve as microbial substrates for the production of acids, thus contributing to the higher acids production. The absolute amount of NDS in the LP and MIX was higher ( $\mathrm{p}<$ 0.01 ) than LB, while the CK had the lowest amount of NDS $(\mathrm{p}<0.01)$. The WSC is the mainly component of NDS. It was reported that WSC is the best source of fermentable material for the production of high quality silages by LAB [25]. For all the groups, the amount of WSC decreased with the greater ensilage time, and more than half of WSC absolute amount was lost after $28 \mathrm{~d}$ of ensilage. The weight of WSC in the LB was lowest $(\mathrm{p}<0.01)$ because $\mathrm{CO}_{2}$ is formed during the conversion of lactic acid to acetic acid and 1,2-propanediol in the heterofermentative fermentation process, which leads to greater WSC loss [26]. While the LP retained a relatively high WSC content after $28 \mathrm{~d}$ of ensilage, these results are in accordance with the acid production during ensiling.

After the 28-d I. lacteus treatment, the absolute amount of DM was calculated based on the data presented in the Table
3 and further decreased (Table 4). However, the rate of degradation of DM, cellulose, hemicellulose and ADL after the $I$. lacteus treatment slowed with prolonged ensilage because the lowering of $\mathrm{pH}$ probably inhibited the growth of I. lacteus. The DM and cellulose amount of the CK after I. lacteus treatment was lower than the amount in the other groups of the same period $(\mathrm{p}<0.01)$, which is probably because the aerobic bacterial consumed more of the substrates in the CKI. A lower hemicellulose and ADL weight was found in $3 \mathrm{~d}, 7 \mathrm{~d}$, and $14 \mathrm{~d}$ LPI $(\mathrm{p}<0.01)$, and the change of hemicellulose is accompanied with the loss of the ADL. Interestingly, the lowest $(\mathrm{p}<0.01)$ ADL amount and the highest amount of NDS and WSC were observed in the 3-d MIXI ( $p<0.01$ ), which is consistent with the speed of I. lacteus growth.

In vitro gas production of corn stover silage before and after I. lacteus treatment

The silage inoculated with LAB presented higher IVGP than the CK ( $\mathrm{p}<0.01$; Figure 2a). With prolonged ensilage, the IVGP gradually decreased (Figure 2a). The IVGP of samples 
Table 4. Chemical composition ( $\mathrm{g}$ ) of corn stover after Irpex lacteus treatment of 3, 7, 14, and $28 \mathrm{~d}$ of ensilage.

\begin{tabular}{|c|c|c|c|c|c|c|c|c|c|}
\hline \multirow{2}{*}{ Items } & \multirow{2}{*}{ Treatments } & \multicolumn{4}{|c|}{ Days of silage } & \multirow{2}{*}{ SEM } & \multicolumn{3}{|c|}{$p$-value ${ }^{1)}$} \\
\hline & & $3 d$ & $7 \mathrm{~d}$ & $14 \mathrm{~d}$ & $28 d$ & & $T$ & D & $T \times D$ \\
\hline \multirow[t]{4}{*}{$\mathrm{DM}$} & CKI & $793^{\mathrm{Cd}}$ & $814^{\mathrm{cc}}$ & $824^{\mathrm{cb}}$ & $840^{\mathrm{Ca}}$ & 3.70 & $<0.001$ & $<0.001$ & $<0.001$ \\
\hline & LPI & $828^{B b}$ & $831^{\mathrm{Bb}}$ & $870^{\mathrm{Aa}}$ & $872^{\mathrm{Aa}}$ & & & & \\
\hline & LBI & $822^{\mathrm{Bb}}$ & $828^{\mathrm{Bb}}$ & $829^{c b}$ & $850^{\mathrm{Ba}}$ & & & & \\
\hline & MIXI & $840^{A C}$ & $841^{A c}$ & $847^{\mathrm{Bb}}$ & $869^{\mathrm{Aa}}$ & & & & \\
\hline \multirow[t]{4}{*}{ Cell } & CKI & $265^{B b}$ & $271^{\mathrm{Ba}}$ & $274^{\mathrm{Ca}}$ & $277^{\mathrm{Ca}}$ & 2.40 & $<0.001$ & $<0.001$ & $<0.001$ \\
\hline & LPI & $277^{A B C}$ & $288^{A b}$ & $306^{\mathrm{Aa}}$ & $308^{\mathrm{Aa}}$ & & & & \\
\hline & LBI & $272^{A B b}$ & $279^{A B a b}$ & $286^{B C a b}$ & $293^{\mathrm{Ba}}$ & & & & \\
\hline & MIXI & $285^{\mathrm{Aa}}$ & $283^{A B a}$ & $291^{\mathrm{Ba}}$ & $274^{\mathrm{cb}}$ & & & & \\
\hline \multirow[t]{4}{*}{$\mathrm{HC}$} & CKI & $168^{b}$ & $171^{\mathrm{Ab}}$ & $179^{A b}$ & $198^{\mathrm{a}}$ & 2.42 & $<0.001$ & $<0.001$ & $<0.351$ \\
\hline & LPI & $145^{b}$ & $151^{\mathrm{Bb}}$ & $164^{\mathrm{Bab}}$ & $174^{a}$ & & & & \\
\hline & LBI & 164 & $164^{A B}$ & $179^{A}$ & 172 & & & & \\
\hline & MIXI & $151^{b}$ & $161^{A B a b}$ & $169^{\mathrm{ABab}}$ & $173^{\mathrm{a}}$ & & & & \\
\hline \multirow[t]{4}{*}{$A D L$} & CKI & $89.3^{A C}$ & $90.1^{c}$ & $95.6^{\mathrm{Ab}}$ & $102^{a}$ & 1.85 & 0.006 & $<0.001$ & 0.002 \\
\hline & LPI & $77.3^{\mathrm{Bb}}$ & $79.2^{b}$ & $85.8^{\mathrm{Bb}}$ & $106^{\mathrm{a}}$ & & & & \\
\hline & LBI & $79.7^{B C}$ & $86.1^{b}$ & $86.5^{\mathrm{Bb}}$ & $98.7^{\mathrm{a}}$ & & & & \\
\hline & MIXI & $71.2^{\mathrm{Cb}}$ & $96.7^{\mathrm{a}}$ & $99.2^{\mathrm{Aa}}$ & $104^{a}$ & & & & \\
\hline \multirow[t]{4}{*}{ NDS } & CKI & $270^{C}$ & $283^{c}$ & $275^{B}$ & $260^{C}$ & 3.87 & $<0.001$ & $<0.001$ & $<0.001$ \\
\hline & LPI & $328^{\mathrm{Aa}}$ & $320^{\mathrm{Aab}}$ & $314^{A b}$ & $284^{B C}$ & & & & \\
\hline & LBI & $306^{\mathrm{Ba}}$ & $299^{B C a b}$ & $277^{B C}$ & $286^{B b c}$ & & & & \\
\hline & MIXI & $333^{\mathrm{Aa}}$ & $307^{A B b}$ & $288^{A B C}$ & $318^{A b}$ & & & & \\
\hline \multirow[t]{4}{*}{ WSC } & CKI & $12.7^{\mathrm{Ba}}$ & $10.4^{b}$ & $11.9^{\text {ABab }}$ & $10.6^{\mathrm{Bb}}$ & 0.54 & $<0.001$ & $<0.001$ & 0.001 \\
\hline & LPI & $13.7^{\mathrm{Ba}}$ & $13.5^{\mathrm{a}}$ & $13.2^{\mathrm{Aa}}$ & $12.2^{\mathrm{Bb}}$ & & & & \\
\hline & LBI & $12.9^{\mathrm{Ba}}$ & $11.1^{b}$ & $9.1^{B C}$ & $13.5^{\mathrm{Ba}}$ & & & & \\
\hline & MIXI & $21.1^{\mathrm{Aa}}$ & $11.7^{c}$ & $12.3^{A B C}$ & $18.3^{\mathrm{Ab}}$ & & & & \\
\hline
\end{tabular}

SEM, standard error of the mean; DM, dry matter; CKI, I. lacteus treatment of corn stover silage uninoculated with LAB; LPI, I. lacteus treatment of silage inoculated with Lactobacillus plantarum; LBI, I. lacteus treatment of silage inoculated with Lactobacillus buchneri; MIXI, I. lacteus treatment of silage inoculated with mixed LAB; Cell, cellulose; $H C$, hemicellulose; $A D L$, acid detergent lignin; NDS, neutral detergent solute; WSC, water soluble carbohydrate.

${ }^{1)} \mathrm{T}$, effect of $I$. lacteus treatment of different silges; $D$, effect of silage time; $T \times D$, interaction between treatment and silage time. Means in the same row ${ }^{\left({ }^{-d}\right)}$ or in the same column ${ }^{(A-C)}$ with different superscripts differ $(p<0.05)$.

that spent different time's in silage indicates that the more time in silage, the less accessible nutrients utilized by the rumen microorganisms, which is consistent with the changes of DM, cellulose, hemicellulose, NDS, and WSC content during ensiling. The 3-d LP showed a higher IVGP than other 3 - $d$ silage groups $(\mathrm{p}<0.01)$, and a $20.5 \%$ increase compared with the raw stover. The increased IVGP in 3-d LP is probably due to $L$. plantarum decreasing the $\mathrm{pH}$, and raising the lactate:acetate ratio [27]. Also, the improved the silage quality, which preserved more true protein during silage fermentation than was present in the CK, which in turn increased in vitro ruminal microbial growth [28]. In addition, although heterofermentation of L. buchneri can improve the aerobic stability of the corn silage, it will cause substrate nutrient loss due to carbon dioxide gas production. That is the reason why IVGP is higher in LP than LB. In addition, the gas production can be divided into two or three phases which were caused by the fermentation of the soluble, insoluble but degradable, and undegradable proportions. Soluble components have the highest contribution to the gas production during the first phase and the insoluble components mainly con- tribute to the gas production of the second phase [29]. The IVGP rate of the CK was higher than other groups during the first $12 \mathrm{~h}$ (Figure $2 \mathrm{~b}$ ), suggesting a greater soluble portion in the 3-d CK corn stover silage. However, the $72 \mathrm{~h}$ total IVGP of the CK was lower than that of the other three groups. After $12 \mathrm{~h}$, not only did the IVGP rate of 3-d LP silage increased, but also the volume of the gas was higher than other 3 - $d$ silage groups $(p<0.01$; Figure $2 b)$. The total IVGP of the silage samples indicated that the LAB can improve the silage quality of the corn stover, especially the silage inoculated with L. plantarum.

For the silage treated with I. lacteus, the 3-d silage with $I$. lacteus treatment showed a higher IVGP than other periods of silages treated with the fungus (Figure 2c). At $3 \mathrm{~d}$ of ensiling, the $\mathrm{pH}$ and amount of organic acids of the samples are probably more appropriate for the I. lacteus growth, which allows it to more effectively degrade the $\mathrm{ADL}$; therefore, the cellulose was more accessible to the rumen microorganisms. With prolonged ensilage, the accumulation of organic acid might inhibit the fungus growth [5]. The highest $(\mathrm{p}<0.01)$ IVGP was observed in the 3-d MIXI, which reached 246.6 
(a)
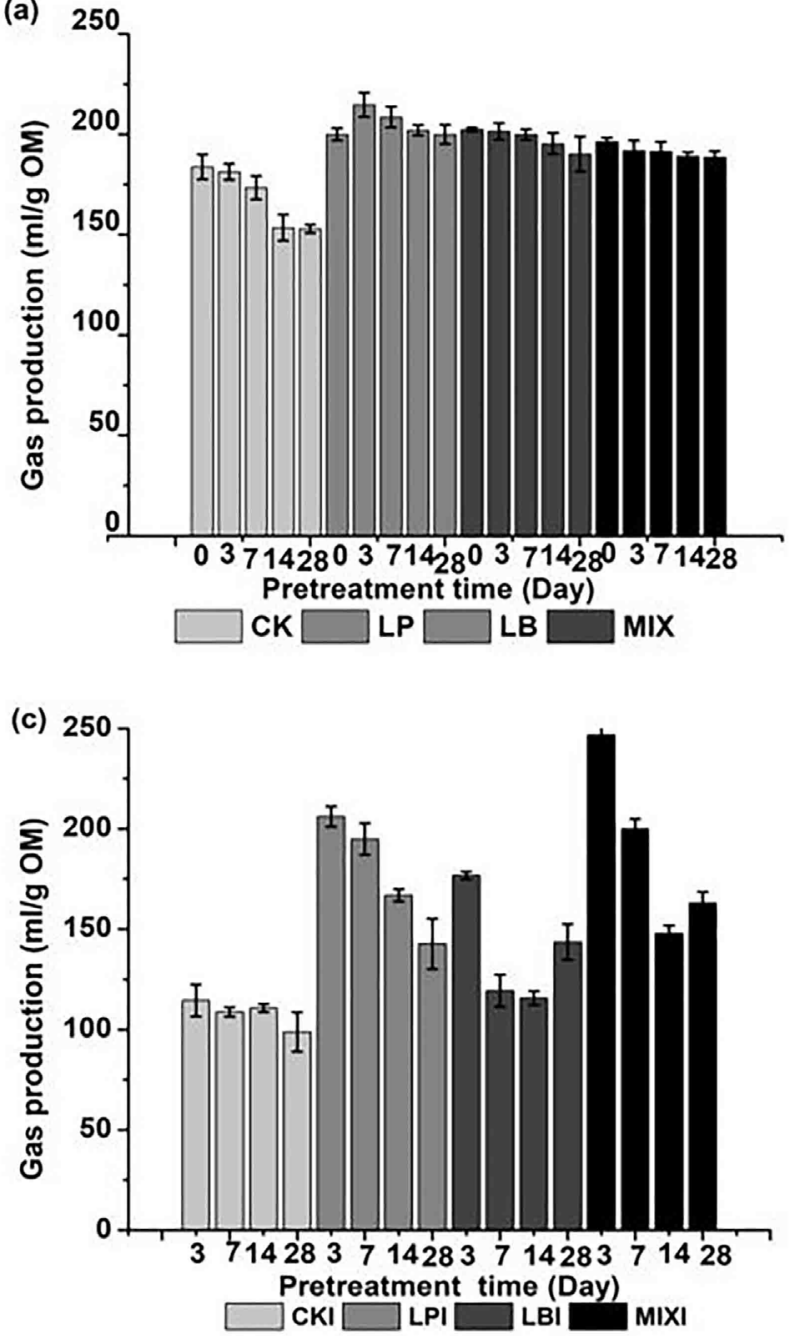

(b)

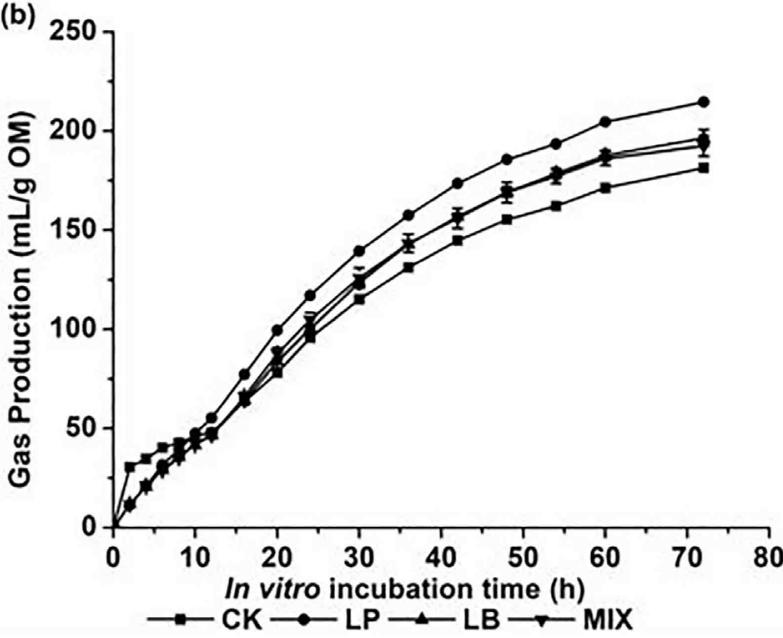

(d)

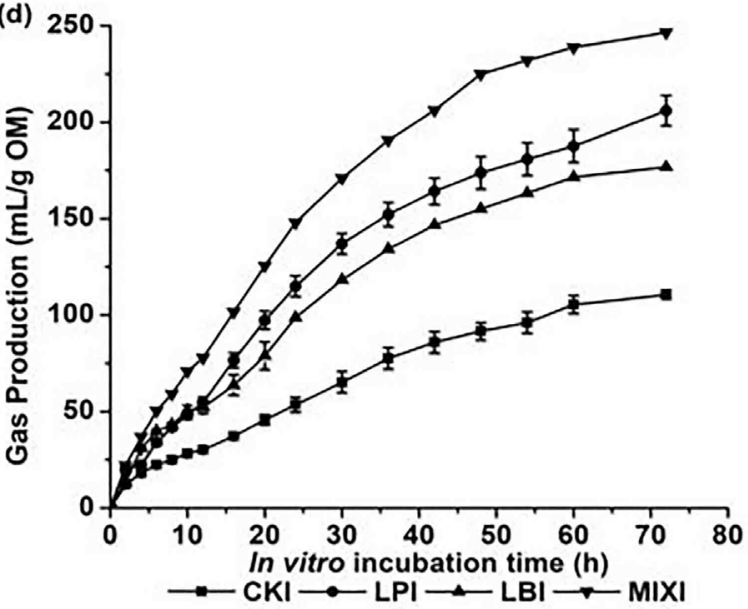

Figure 2. In vitro gas production (IVGP) of different periods of corn stover silage (a), and the IVGP dynamic changes of $3 \mathrm{~d}$ different silage groups (b); as well as the IVGP of Irpex lacteus treatment of the different periods of silage (c), and the IVGP dynamic changes of the I. lacteus treatment of the $3 \mathrm{~d}$ different silage (d). CK, silage uninoculated with $L A B ; L_{1}$, the silage inoculated with Lactobacillus planturam; $L B$, the silage inoculated with Lactobacillus buchneri; $M I X$, the silage inoculated with the mixed L. planturam and L. buchneri; CKI, I. lacteus treatment of corn stover silage uninoculated with LAB; LPI, I. lacteus treatment of silage inoculated with Lactobacillus plantarum; LBI, I. lacteus treatment of silage inoculated with Lactobacillus buchneri; MIXI, I. lacteus treatment of silage inoculated with mixed L. plantarum and L. buchneri. Data are presented as means of three replicates (mean \pm standard deviation).

$\mathrm{mL} / \mathrm{g} \mathrm{OM}$, significantly higher than the IVGP of the 3 -d CKI, which was only $114.5 \mathrm{~mL} / \mathrm{g} \mathrm{OM}$ ( $\mathrm{p}<0.01$; Figure $2 \mathrm{c}$ ), and also higher than the IVGP of the raw corn stover, which was $164.8 \mathrm{~mL} / \mathrm{g} \mathrm{OM}(\mathrm{p}<0.01)$ (data not shown). The IVGP of the 3 -d and 7-d LPI was higher than the $3-d$ LBI ( $<<0.01$; Figure $2 c)$. Although L. buchneri can improve the aerobic stability of the silage so that it is better for the I. lacteus growth, the fungus growth is even greater in the silage samples inoculated with L. plantarum and the lactic acid, NDS, and WSC content of the 3-d LPI is higher than the LBI. The ADL content of the LPI is lower than that of LBI, therefore, which may explain the higher IVGP after I. lacteus treatment of LP than LB. The IVGP rate of the 3 - $d$ MIXI was highest $(p<0.01$; Figure $2 \mathrm{~d}$ ). This is because it had the lowest content of ADL and the highest content of NDS and WSC. The increased amount of
IVGP was not different from that of our previous research's result of an IVGP of $249.74 \mathrm{~mL} / \mathrm{g}$ OM after the same days of I. lacteus treatment of the sterilized corn stover [30], indicating that the present method is effective and efficient. The IVGP rate of the $3-\mathrm{d}$ CKI was lowest ( $\mathrm{p}<0.01$; Figure $2 \mathrm{~d}$ ), lower than even the raw stover $(\mathrm{p}<0.01)$. This is probably due to the poor quality of the silage which was easily contaminated by the aerobic bacteria, which inhibited the growth of the I. lacteus. Moreover, contaminating microorganisms also consumed a portion of nutritious portion of the samples during the fungal treatment.

\section{CONCLUSION}

This study sought to evaluate an alternative method to prepare 
corn stover for I. lacteus treatment to optimize its nutritional value. The IVGP was improved after $28 \mathrm{~d}$ of I. lacteus treatment of the 3-d corn stover silage pre-treated with the mixed of L. plantarum and L. buchneri. Further work is needed to evaluate the effect of the combination of ensiling with fungustreatment on in situ degradation and ruminal fermentation. Overall, the combination of I. lacteus treatment for a short period of silage inoculated with a mixture of LAB is a promising technology alternative to high cost sterilization before the fungal treatment.

\section{CONFLICT OF INTEREST}

We certify that there is no conflict of interest with any financial organization regarding the material discussed in the manuscript.

\section{ACKNOWLEDGMENTS}

The authors wish to thank for the help from Washington State University's writing center in the English corrections. We also thank LetPub (www.letpub.com) for its linguistic assistance during the preparation of this manuscript. This work was supported by Ministry of Science and Technology of the People's Republic of China (No. 2015DFG32360).

\section{REFERENCES}

1. Van Kuijk SJA, Sonnenberg ASM, Baars JJP, Hendriks WH, Cone JW. Fungal treated lignocellulosic biomass as ruminant feed ingredient: a review. Biotechnol Adv 2015;33:191-202. https://doi.org/10.1016/j.biotechadv.2014.10.014

2. Chaturvedi V, Verma P. An overview of key pretreatment processes employed for bioconversion of lignocellulosic biomass into biofuels and value added products. 3 Biotech 2013;3:415-31. https://doi.org/10.1007/s13205-013-0167-8

3. Vasco-Correa J, Ge X, Li Y. Fungal pretreatment of nonsterile miscanthus for enhanced enzymatic hydrolysis. Bioresour Technol 2016;203:118-23. https://doi.org/10.1016/ j.biortech.2015.12.018

4. Song L, Yu H, Ma F, Zhang X. Biological pretreatment under non-sterile conditions for enzymatic hydrolysis of corn stover. BioResources 2013;8:3802-16. https://doi.org/10.15376/biores. 8.3.3802-3816

5. Liu S, Li X, Wu S, et al. Fungal pretreatment by Phanerochaete chrysosporium for enhancement of biogas production from corn stover silage. Appl Biochem Biotechnol 2014;174:190718. https://doi.org/10.1007/s12010-014-1185-7

6. Thomsen ST, Londono JE, Ambye-Jensen M, Heiske S, Kadar $\mathrm{Z}$, Meyer AS. Combination of ensiling and fungal delignification as effective wheat straw pretreatment. Biotechnol Biofuels 2016;9:16. https://doi.org/10.1186/s13068-016-0437-X
7. Zheng ML, Niu DZ, Jiang D, Zuo SS, Xu CC. Dynamics of microbial community during ensiling direct-cut alfalfa with and without LAB inoculant and sugar. J Appl Microbiol 2017; 122:1456-70. https://doi.org/10.1111/jam.13456

8. Shrestha S, Fonoll X, Khanal SK, Raskin L. Biological strategies for enhanced hydrolysis of lignocellulosic biomass during anaerobic digestion: current status and future perspectives. Bioresour Technol 2017;245:1245-57. https://doi.org/10.1016/ j.biortech.2017.08.089

9. Xu Z, He H, Zhang S, Kong J. Effects of inoculants Lactobacillus brevis and Lactobacillus parafarraginis on the fermentation characteristics and microbial communities of corn stover silage. Sci Rep 2017;7:13614. https://doi.org/10.1038/ s41598-017-14052-1

10. Johnston SR, Boddy L, Weightman AJ. Bacteria in decomposing wood and their interactions with wood-decay fungi. FEMS Microbiol Ecol 2016;92:fiw179. https://doi.org/10. 1093/femsec/fiw179

11.Xu C, Ma F, Zhang X. Lignocellulose degradation and enzyme production by Irpex lacteus CD2 during solid-state fermentation of corn stover. J Biosci Bioeng 2009;108:372-5. https:// doi.org/10.1016/j.jbiosc.2009.04.023

12.Zuo S, Niu D, Zheng M, et al. Effect of Irpex lacteus, Pleurotus ostreatus and Pleurotus cystidiosus pretreatment of corn stover on its improvement of the in vitro rumen fermentation. J Sci Food Agric 2018;98:4287-95. https://doi.org/10.1002/jsfa.8951

13.Xu C, Cai Y, Moriya N, Ogawa M. Nutritive value for ruminants of green tea grounds as a replacement of brewers' grains in totally mixed ration silage. Anim Feed Sci Technol 2007; 138:228-38. https://doi.org/10.1016/j.anifeedsci.2006.11.014

14. Owens VN, Albrecht KA, Muck RE, Duke SH. Protein degradation and fermentation characteristics of red clover and alfalfa silage harvested with varying levels of total nonstructural carbohydrates. Crop Sci 1999;39:1873-80. https:/doi.org/ 10.2135/cropsci1999.3961873x

15. Van Soest PJ, Robertson JB, Lewis BA. Methods for dietary fiber, neutral detergent fiber, and nonstarch polysaccharides in relation to animal nutrition. J Dairy Sci 1991;74:3583-97. https://doi.org/10.3168/jds.S0022-0302(91)78551-2

16. Van Kuijk SJA, Sonnenberg ASM, Baars JJP, Hendriks WH, Cone JW. Fungal treatment of lignocellulosic biomass: Importance of fungal species, colonization and time on chemical composition and in vitro rumen degradability. Anim Feed Sci Technol 2015;209:40-50. https://doi.org/10.1016/j.ani feedsci.2015.07.026

17. Menke KH, Steingass H. Estimation of the energetic feed value obtained from chemical analysis and in vitro gas production using rumen fluid. Anim Res Dev 1988;28:7-55.

18. Weinberg ZG, Muck RE. New trends and opportunities in the development and use of inoculants for silage. FEMS Microbiol Rev 1996;19:53-68. https://doi.org/10.1016/0168-6445(96) 00025-3 
19. Filya I. The effect of Lactobacillus buchneri, with or without homofermentative lactic acid bacteria, on the fermentation, aerobic stability and ruminal degradability of wheat, sorghum and maize silages. J Appl Microbiol 2003;95:1080-6. https:// doi.org/10.1046/j.1365-2672.2003.02081.x

20. Muck RE. Silage microbiology and its control through additives. Rev Bras Zootec 2010;39:183-91. https://doi.org/10.1590/ S1516-35982010001300021

21.Ennahar S, Cai Y, Fujita Y. Phylogenetic diversity of lactic acid bacteria associated with paddy rice silage as determined by 16S ribosomal DNA analysis. Appl Environ Microb 2003;69: 444-51. https://doi.org/10.1128/AEM.69.1.444-451.2003

22. Weinberg ZG, Ashbell G, Hen Y, Azrieli A. The effect of cellulase and hemicellulase plus pectinase on the aerobic stability and fibre analysis of peas and wheat silages. Anim Feed Sci Technol 1995;55:287-93. https://doi.org/10.1016/ 0377-8401(95)00785-L

23. Borràs E, Caminal G, Sarrà M, Novotný Č. Effect of soil bacteria on the ability of polycyclic aromatic hydrocarbons (PAHs) removal by Trametes versicolor and Irpex lacteus from contaminated soil. Soil Biol Biochem 2010;42:2087-93. https://doi. org/10.1016/j.soilbio.2010.08.003

24. Yahaya M, Kimura A, Harai J, et al. Effect of length of ensiling on silo degradation and digestibility of structural carbohydrates of lucerne and orchardgrass. Anim Feed Sci Technol 2001; 92:141-8. https://doi.org/10.1016/S0377-8401(01)00265-6
25. Rooke JA, Hatfield RD. Biochemistry of ensiling. In: Buxton D, Muck R, Harrison J, Editors. Silage science and technology. Madison, WI, USA: American Society of Agronomy; 2003. pp. 95-139.

26.Driehuis F, Oude Elferink SJWH, Van Wikselaar PG. Fermentation characteristics and aerobic stability of grass silage inoculated with Lactobacillus buchneri, with or without homofermentative lactic acid bacteria. Grass Forage Sci 2001;56:33043. https://doi.org/10.1046/j.1365-2494.2001.00282.x

27. Weinberg ZG, Szakacs G, Ashbell G, Hen Y. The effect of Lactobacillus buchneri and L. plantarum, applied at ensiling, on the ensiling fermentation and aerobic stability of wheat and sorghum silages. J Ind Microbiol Biotechnol 1999;23: 218-22. https://doi.org/10.1038/sj.jim.2900726

28. Contreras-Govea FE, Muck RE, Broderick GA, Weimer PJ. Lactobacillus plantarum effects on silage fermentation and in vitro microbial yield. Anim Feed Sci Technol 2013;179:618. https://doi.org/10.1016/j.anifeedsci.2012.11.008

29. Cone JW, Van Gelder AH, Visscher GJW, Oudshoorn L. Influence of rumen fluid and substrate concentration on fermentation kinetics measured with a fully automated time related gas production apparatus. Anim Feed Sci Technol 1996;61: 113-28. https://doi.org/10.1016/0377-8401(96)00950-9

30.Zuo S, Niu D, Jiang D, et al. Effect of white-rot fungal treatments on the in vitro rumen degradability of two kinds of corn stover. BioResources 2019;14:895-907. 